\title{
Short-term effects of Finnish sauna bathing on blood-based markers of cardiovascular function in non-naive sauna users
}

\author{
Setor K. Kunutsor ${ }^{1,2} \cdot$ Arja Häkkinen $^{3} \cdot$ Francesco Zaccardi $^{4} \cdot$ Tanjaniina Laukkanen $^{5} \cdot$ Earric Lee $^{3} \cdot$ Peter Willeit $^{6,7}$. \\ Hassan Khan ${ }^{8}$. Jari A. Laukkanen ${ }^{3,5,9}$ (1)
}

Received: 29 January 2018 / Accepted: 15 June 2018 / Published online: 3 July 2018

(c) The Author(s) 2018

\begin{abstract}
Emerging evidence suggests that sauna bathing is associated with reduced risk of cardiovascular and all-cause mortality events. However, the biochemical pathways by which sauna bathing might confer its effects on cardiovascular function are not certain. We aimed to study the acute effects of Finnish sauna bathing on various blood-based cardiovascular biomarkers. The study included 102 non-naive sauna users (54\% male) with mean age of 51.9 years, who had at least one cardiovascular risk factor. Participants underwent a 30-min single sauna session (mean temperature, $73{ }^{\circ} \mathrm{C}$ ). Biochemical profiling was conducted before, immediately after sauna and 30-min post-sauna. Overall median N-terminal pro-B-type natriuretic peptide (NT-proBNP) level ( $n=20$ participants) was $46.0 \mathrm{ng} / \mathrm{L}$ before sauna exposure, which increased to $50.5 \mathrm{ng} / \mathrm{limmediately}$ after sauna (median change, $+12.00 \% ; p<0.001$ ) and remained persistent at 30 -min post-sauna (median change from pre-sauna to post-30-min sauna, $+13.93 \%$; $p<0.001$ ). The changes were more evident in males compared with females. There were no significant changes in overall levels of high sensitivity C-reactive protein, creatine kinase, high sensitivity troponin I, and creatine kinase-MBm. However, levels of creatine kinase increased in males (median change immediately after sauna, $+2.99 \% ; p=0.024$ ). Levels of NT-proBNP increased after sauna exposure. The increase in levels of creatine kinase was more evident in males. Long-term interventional studies are warranted to evaluate if these biomarkers are involved in pathways underlying the associations of sauna bathing with cardiovascular outcomes.
\end{abstract}

Keywords Sauna bathing $\cdot$ Experimental study $\cdot$ Cardiovascular disease $\cdot$ Biomarkers

\section{Introduction}

Repeated passive heat therapy has been shown to have beneficial effects on the cardiovascular system by improving endothelial function, arterial stiffness, and microvascular

Jari A. Laukkanen

jariantero.laukkanen@uef.fi

1 National Institute for Health Research Bristol Biomedical Research Centre, University Hospitals Bristol NHS Foundation Trust, University of Bristol, Bristol, UK

2 Musculoskeletal Research Unit, Translational Health Sciences, Bristol Medical School, University of Bristol, Learning \& Research Building (Level 1), Southmead Hospital, Bristol BS10 5NB, UK

3 Faculty of Sport and Health Sciences, University of Jyväskylä, Jyvaskyla, Finland

4 Diabetes Research Centre, Leicester General Hospital, University of Leicester, Leicester, UK function; reducing carotid intima media thickness, blood pressure, markers of oxidative stress, and brain natriuretic peptides; as well as increasing parasympathetic and decreasing sympathetic nervous activity [1-5]. Sauna bathing, a form of passive heat therapy, is an activity which is a
5 Institute of Public Health and Clinical Nutrition, University of Eastern Finland, P.O. Box 1627, 70211 Kuopio, Finland

6 Department of Public Health and Primary Care, University of Cambridge, Cambridge, UK

7 Department of Neurology, Medical University Innsbruck, Innsbruck, Austria

8 Division of Cardiology, Department of Medicine, Emory University, Atlanta, GA, USA

9 Department of Internal Medicine, Central Finland Health Care District, Jyvaskyla, Finland 
tradition in Finland and commonly used for relaxation and pleasure and is becoming increasingly popular in many other cultures $[6,7]$. Finnish sauna bathing has been linked to improved cardiovascular function as well as several health benefits. Emerging evidence suggests that regular sauna bathing is associated with lower blood pressure [8], reduced risk of cardiovascular disease (CVD) mortality [9], stroke [10], dementia [11], and pulmonary diseases [12, 13], as well as reduced all-cause mortality risk [9]. The specific cardiovascular adaptations produced by long-term sauna bathing is not certain, but the effects of sauna bathing on cardiometabolic health outcomes have been linked to its beneficial impact on circulatory and cardiovascular function. Regular long-term sauna bathing has been shown to produce blood pressure lowering effects [14] as well as reducing levels of markers of inflammation $[15,16]$.

Evidence on the beneficial effects of sauna bathing on circulatory and cardiovascular function has mostly been based on studies evaluating the short-term effects of sauna. Shortterm or acute sauna exposure has been shown to produce blood pressure lowering effects [17], decrease peripheral vascular resistance $[17,18]$ and arterial stiffness $[8,19]$ as well as improve arterial compliance [19]. Short-term sauna exposure also activates the sympathetic nervous system and the renin-angiotensin-aldosterone system, and the hypothalamus-pituitary-adrenal hormonal axis with short-term increases in levels of their associated hormones [20]. Other potential pathways by which sauna therapy may exert its cardioprotective effects are via positive modulation in levels of blood-based established cardiovascular risk factors such as lipids, glucose, markers of insulin resistance, natriuretic peptides, and cardiac troponins. There is, however, limited evidence on the effects of short-term sauna exposure on these circulating biomarkers. Several studies on the short-term effects of other passive heat therapies such as Waon therapy, infrared saunas, intermittent warm water immersion, and whole-body hyperthermia have, however, been shown to have beneficial effects on parameters of cardiovascular function such as (1) reductions in concentrations of circulating arterial endothelial- and platelet-derived microparticles [21] and markers of inflammation and oxidative stress [3, 22-25]; (2) protection against impaired vascular function [26]; (3) induction in systemic and hemodynamic responses (blood pressure lowering and shear rate increases) [27, 28] and improved vascular function [29]; and (4) reduction in arterial stiffness [30].

Given the overall evidence which suggests that short-term heat therapy may produce widespread beneficial effects on vascular function, our hypothesis was that a short-term exposure to Finnish sauna will produce beneficial changes in levels of circulating cardiovascular biomarkers. In this context, we conducted this exploratory experimental noncontrolled study to show the effects of 30 min of Finnish sauna bathing on several parameters of cardiovascular function. We have previously reported on the potential beneficial effects of acute sauna exposure on arterial stiffness and compliance, blood pressure, haematological variables, as well as renal markers $[8,19]$. In this report, we study the effects of 30 min of Finnish sauna bathing on circulating blood-based markers of cardiovascular function [such as high sensitivity C-reactive protein (hsCRP), creatine kinase, hs-troponin I, creatine kinase-MBm, and $\mathrm{N}$-terminal pro-B-type natriuretic peptide (NT-proBNP)], immediately after sauna and 30-min post-sauna.

\section{Materials and methods}

\section{Participants}

We recruited 110 participants without pre-existing CVD from the city of Jyväskylä, Central Finland region, through the local out-of-hospital community health care center. Study participants were asymptomatic with at least one cardiovascular risk factor, such as a history of smoking, dyslipidaemia, hypertension, obesity, diabetes, or family history of coronary heart disease (CHD). Participants $(n=8)$ with any form of acute or pre-existing CVD were excluded from the study. A total of 102 participants were finally included in the study. Given the challenge in recruiting naive or non-sauna users to sauna studies in Finland, because the majority of the population use sauna regularly, our study sample were all sauna users. Prior to study entry, participants were provided with information about the research purposes and measurement procedures and were screened by a cardiac specialist. The study design and protocol were approved by the institutional review board of the Central Finland Hospital District ethical committee, Jyväskylä, Finland (Dnro 5U/2016). All study participants provided written informed consent.

\section{Baseline assessments and clinical examination}

Baseline data collection, as well as a clinical evaluation, was conducted on separate days prior to the experiment. Baseline assessments and sauna measurements were conducted during June and November 2016. Assessment of demographics, lifestyle factors (e.g., smoking, physical activity, and sauna bathing habits), prevalent diseases, and regular use of medication were based on a detailed self-reported questionnaire which was checked by a cardiologist during screening. Physical activity and sauna bathing habits over the past 1 year were assessed. The duration and frequency of physical activity were also explored. Information collected on regular sauna bathing habits was based on frequency (weekly sauna sessions), duration, and temperature (measured using a thermometer located in the sauna room). Medical history, 
physical examination, and resting electrocardiogram (ECG) were assessed during the screening visit. Resting blood pressure was estimated as the mean of two measurements obtained, while the participant was in the supine position, based on a standardized measurement protocol. Body mass index (BMI) was calculated by dividing weight in kilograms by the square of height in meters.

\section{Finnish sauna exposure}

The traditional Finnish sauna with dry air and relatively high temperature was used as our exposure [9]. It consisted of a typical Finnish sauna bathing session which lasted for $30 \mathrm{~min}$. However, there was a short, 2-min shower after the first $15 \mathrm{~min}$ [8]. Sauna bathing sessions took place between 9.00 and $11.00 \mathrm{~h}$ on the specified study days. Sauna rooms were gender specific and all participants wore their own swim suits during the sauna sessions. Only one participant was allowed in the sauna bath at a time. Sauna temperature was set at $80^{\circ} \mathrm{C}$ and this was controlled and monitored by internal temperature sensors designed by Harvia Oy, Finland. Temperature assessment was continuous with the use of a two-channel thermometer in the sauna room and the data were collected during experiment. The temperature sensor also monitored the humidity of the sauna room. Based on overall data collected, the mean \pm standard deviation (SD) temperature was $73 \pm 2{ }^{\circ} \mathrm{C}$ with a relative humidity of 10-20\%. Study participants were monitored and supervised by a physician and were allowed to leave the sauna at any time they felt any discomfort. All participants underwent the recommended sauna protocol without any problems. Participants were given $500 \mathrm{~mL}$ of still water at room temperature to drink during the entire sauna session, and including the recovery period post-sauna. The recovery period was for 30 min which involved resting in a designated relaxing waiting lounge (mean temperature $21^{\circ} \mathrm{C}$ ). Body temperature was measured for each participant from the ear.

\section{Assessment of laboratory markers}

Non-fasting blood samples were taken about $2 \mathrm{~h}$ prior to sauna sessions. Participants were instructed to abstain from strenuous physical activity $24 \mathrm{~h}$ before the blood samples were taken. Venous blood samples were collected by a qualified laboratory technician from the antecubital vein in the sitting position, using sterile needles, and were collected into serum and plasma tubes (BD Vacutainer, Plymouth. UK). Whole blood samples were stored for $10 \mathrm{~min}$ before being centrifuged at $3500 \mathrm{rpm}$ (Megafuge, Heraeus, Germany) and serum and plasma samples stored at $-80{ }^{\circ} \mathrm{C}$ until analysis. Serum total cholesterol, high-density lipoprotein (HDL), low-density lipoprotein (LDL), Apolipoprotein A1 (ApoA1), Apolipoprotein B (Apo B), triglycerides, and plasma glucose concentrations were measured using a spectrophotometry analyzer (Konelab 20XTi, Thermo Fisher Scientific, Vantaa, Finland). Venous blood samples for the determination of plasma inflammatory markers and cardiac biomarkers were analyzed using chemiluminecent immunoassay by Siemens Immulite 2000 XPi (Siemens Healthcare Diagnostics Products Ltd., Llanberies, UK) analyzer. Measurements of NT-proBNP were conducted in only a random sample of participants because of the high costs associated with these assays. Creatine kinase was measured in heparinised plasma by Konelab 20XTi, (Thermo Fisher Scientific, Vantaa, Finland). All biomarkers were assessed before and after sauna.

\section{Statistics}

All the cardiovascular biomarkers (hsCRP, creatine kinase, hs-troponin I, creatine kinase-MBm, and NT-proBNP) evaluated were skewed and thus were log transformed to approximate normal distributions. Data are presented as means (SD) or median (interquartile range, IQR) for continuous variables according to their distribution and as proportions for categorical variables. Normality was checked using the Shapiro-Wilk test as well as through observing the Q-Q plots. Repeated measure analysis of variance (ANOVA) was used to estimate within-group differences and changes by time. Paired $t$ tests were used to compare within-group changes in biomarkers assessed immediately after sauna and 30-min post-sauna. Given the skewness of cardiovascular biomarkers, median percent changes were calculated as they are robust and provide strong reductions in estimation bias and variance in the presence of outliers [31]. A two-sided significance level was set at $p \leq 0.05$. All statistical analyses were carried out with Stata version 14.1 (Stata Corp, College Station, Texas, USA).

\section{Results}

\section{Characteristics of population}

Baseline characteristics of the 102 study participants are shown in Table 1 . The majority of participants were male $(n=56)$. The mean (SD) of age, BMI, and SBP were 51.9 (SD 9.2) years, $27.9(4.7) \mathrm{kg} / \mathrm{m}^{2}$, and 136 (16) $\mathrm{mmHg}$, respectively. Current smokers made up $14.4 \%$ of the study population. Lipid parameters were generally similar between males and females. Male participants had higher levels of creatine kinase, creatine kinase-MBm, and NTproBNP compared with females. Levels of hsCRP and hstroponin I were higher in female. Levels of these cardiovascular risk markers in study participants were generally within the normal reference ranges. Mean plasma creatinine level was $114.5 \mathrm{U} / \mathrm{L}$ in this population. Dyslipidaemia 
Table 1 Baseline characteristics

\begin{tabular}{|c|c|c|c|c|}
\hline & $N(M / F)$ & Total & $M$ & $F$ \\
\hline \multicolumn{5}{|l|}{ Clinical characteristics } \\
\hline Age (years) & $56 / 46$ & $51.9 \pm 9.2$ & $51.8 \pm 10.1$ & $52.0 \pm 8.3$ \\
\hline Body weight (kg) & $56 / 46$ & $82.7 \pm 16.0$ & $88.9 \pm 13.4$ & $75.5 \pm 15.9$ \\
\hline Body mass index $\left(\mathrm{kg} / \mathrm{m}^{2}\right)$ & $56 / 46$ & $27.2(24.5-30.7)$ & $27.7(25.1-30.6)$ & $26.7(23.8-31.0)$ \\
\hline Smokers & $56 / 46$ & $14(14.4 \%)$ & $9(17.7 \%)$ & $5(10.9 \%)$ \\
\hline Systolic blood pressure $(\mathrm{mmHg})$ & $56 / 46$ & $136.5 \pm 16.2$ & $137.2 \pm 14.4$ & $135.8 \pm 18.3$ \\
\hline Diastolic blood pressure $(\mathrm{mmHg})$ & $56 / 46$ & $82.1 \pm 9.6$ & $84.2 \pm 9.6$ & $79.6 \pm 9.2$ \\
\hline Resting HR (bpm) & $56 / 46$ & $64(59-70)$ & $64(56.5-70)$ & $65(61-70)$ \\
\hline Total cholesterol $\left(\mathrm{Chol}_{\text {tot }} ; \mathrm{mmol} / \mathrm{L}\right)$ & $56 / 46$ & $5.4 \pm 1.0$ & $5.4 \pm 1.1$ & $5.4 \pm 0.9$ \\
\hline Low-density lipoprotein (LDL; mmol/L) & $56 / 46$ & $3.0 \pm 0.8$ & $3.1 \pm 0.8$ & $3.0 \pm 0.8$ \\
\hline High-density lipoprotein (HDL; mmol/L) & $56 / 46$ & $1.4 \pm 0.4$ & $1.3 \pm 0.4$ & $1.5 \pm 0.4$ \\
\hline Triglycerides (mmol/L) & $56 / 46$ & $1.6(1.0-2.3)$ & $1.8(1.2-2.6)$ & $1.3(0.9-2.0)$ \\
\hline Glucose $(\mathrm{mmol} / \mathrm{L})$ & $56 / 46$ & $5.2 \pm 0.9$ & $5.3 \pm 1.0$ & $5 \pm 0.9$ \\
\hline Apo A1 (g/L) & $56 / 46$ & $1.5(1.3-1.7)$ & $1.5(1.3-1.7)$ & $1.6(1.4-1.8)$ \\
\hline Apo B (g/L) & $56 / 46$ & $1.0(0.8-1.2)$ & $1.0(0.8-1.2)$ & $0.9(0.7-1.1)$ \\
\hline \multicolumn{5}{|l|}{ Cardiovascular risk markers } \\
\hline High sensitivity C-reactive protein $(\mathrm{mg} / \mathrm{L})(\mathrm{mg} / \mathrm{L})$ & $54 / 46$ & $1.26(0.52-2.79)$ & $1.12(0.59-3.31)$ & $1.39(0.48-2.51)$ \\
\hline Creatine kinase (U/L) & $54 / 46$ & $114.5(81.0-160.0)$ & $132.5(100.0-189.0)$ & $99.5(71.0-122.0)$ \\
\hline High sensitivity troponin $\mathrm{I}(\mathrm{ng} / \mathrm{mL})$ & $54 / 46$ & $0.003(0.001-0.015)$ & $0.002(0.001-0.014)$ & $0.005(0.001-0.015)$ \\
\hline Creatine kinase-MBm (ng/mL) & $54 / 46$ & $1.39(0.99-2.14)$ & $1.90(1.34-2.67)$ & $1.18(0.71-1.42)$ \\
\hline N-terminal pro-B-type natriuretic peptide (ng/L) & $8 / 12$ & $46.0(32.5-58.0)$ & $48.0(25.5-53.5)$ & $44.0(34.5-74.5)$ \\
\hline \multicolumn{5}{|l|}{ Self-reported conditions and family history } \\
\hline Hypertension & $56 / 46$ & $14(14.3 \%)$ & $11(21.2 \%)$ & $3(6.5 \%)$ \\
\hline Hypercholesterolaemia $^{a}$ & $56 / 44$ & $63(63.0 \%)$ & $37(66.1 \%)$ & $26(59.1 \%)$ \\
\hline Type 1 diabetes & $56 / 46$ & $2(2.0 \%)$ & $1(1.9 \%)$ & $1(2.2 \%)$ \\
\hline Type 2 diabetes & $56 / 46$ & $1(1.0 \%)$ & $1(1.9 \%)$ & $0(0.0 \%)$ \\
\hline Respiratory (incl. Asthma) & $56 / 46$ & $5(5.1 \%)$ & $2(3.8 \%)$ & $3(6.5 \%)$ \\
\hline Thyroid disease (hypo) & $56 / 46$ & $3(3.1 \%)$ & $1(1.9 \%)$ & $2(4.3 \%)$ \\
\hline Skin disease (atopic) & $56 / 46$ & $4(4.1 \%)$ & $3(5.8 \%)$ & $1(2.2 \%)$ \\
\hline Rheumatoid arthritis & $56 / 46$ & $1(1.0 \%)$ & $0(0.0 \%)$ & $1(2.2 \%)$ \\
\hline Family history of coronary heart disease & $56 / 46$ & $33(34.0 \%)$ & $15(29.4 \%)$ & $18(39.1 \%)$ \\
\hline \multicolumn{5}{|l|}{ Self-reported sauna habits and physical activity } \\
\hline Frequency of sauna, times/week & $56 / 46$ & & & \\
\hline 1 & & $16(16.3 \%)$ & $6(11.5 \%)$ & $10(21.7 \%)$ \\
\hline 2 & & $16(16.3 \%)$ & $7(13.5 \%)$ & $9(19.6 \%)$ \\
\hline 3 & & $43(43.9 \%)$ & $23(44.2 \%)$ & $20(43.5 \%)$ \\
\hline 4 & & $23(23.5 \%)$ & $16(30.8 \%)$ & $7(15.2 \%)$ \\
\hline Duration of sauna, minutes/session & $56 / 45$ & & & \\
\hline$<20$ & & $17(17.5 \%)$ & $8(15.4 \%)$ & $9(20.0 \%)$ \\
\hline $20-40$ & & $55(56.7 \%)$ & $28(53.8 \%)$ & $27(60.0 \%)$ \\
\hline $41-60$ & & $21(21.6 \%)$ & $14(26.9 \%)$ & $7(15.6 \%)$ \\
\hline$>60$ & & $4(4.1 \%)$ & $2(3.8 \%)$ & $2(4.4 \%)$ \\
\hline Average temperature of sauna, ${ }^{\circ} \mathrm{C}$ & $56 / 46$ & $72.0 \pm 8.5$ & $73.0 \pm 9.0$ & $70.9 \pm 7.8$ \\
\hline Frequency of physical activity, times/week & $56 / 46$ & & & \\
\hline 0 & & $1(1.6 \%)$ & $1(3.3 \%)$ & $0(0.0 \%)$ \\
\hline 1 & & $16(25.8 \%)$ & $7(23.3 \%)$ & $9(28.1 \%)$ \\
\hline $2-3$ & & $20(32.3 \%)$ & $11(36.7 \%)$ & $9(28.1 \%)$ \\
\hline $4-5$ & & $19(30.6 \%)$ & $9(30.0 \%)$ & $10(31.3 \%)$ \\
\hline$>5$ & & $6(9.7 \%)$ & $2(6.7 \%)$ & $4(12.5 \%)$ \\
\hline Duration of physical activity, minutes/session & $56 / 46$ & & & \\
\hline
\end{tabular}


Table 1 (continued)

\begin{tabular}{lllll}
\hline & $N(M / F)$ & Total & $M$ & $F$ \\
\hline$<20$ & $7(10.0 \%)$ & $2(5.7 \%)$ & $5(14.3 \%)$ & $6(17.1 \%)$ \\
$20-40$ & $18(25.7 \%)$ & $12(34.3 \%)$ & $8(22.9 \%)$ \\
$41-60$ & $19(27.1 \%)$ & $11(31.4 \%)$ & $16(45.7 \%)$ \\
$>60$ & $26(37.1 \%)$ & $10(28.6 \%)$ & 16 \\
\hline
\end{tabular}

Values are reported as mean $\pm \mathrm{SD}$ or median (interquartile range) for continuous variables and $n(\%)$ for categorical variables

$M$ male, $F$ female

${ }^{\mathrm{a}}$ Total Cholesterol $>5.17 \mathrm{mmol} / \mathrm{L}$

(63.0\%) and family history of CHD (34.0\%) were the most common cardiovascular risk factors in the study population, followed by hypertension at $14.3 \%$. Forty-four percent of subjects had both dyslipidaemia and a family history of CHD. A few participants had underlying clinical conditions such as type 1 diabetes (2.0\%), type 2 diabetes $(1.0 \%)$, respiratory diseases $(5.1 \%)$, thyroid disease $(3.1 \%)$, skin disease $(4.0 \%)$, and rheumatoid arthritis (1.0\%). Baseline assessment of sauna bathing showed that the majority of participants used sauna baths 3 times per week (43.9\%). Commonly, a sauna session lasted between 20 and $40 \mathrm{~min}$ for most participants (56.7\%) and the average self-reported temperature was $72{ }^{\circ} \mathrm{C}$. Most participants reported $>1-3$ sessions of physical activity per week (32.3\%) followed by $>3-5$ sessions per week (30.6\%). The majority of participants $(37.1 \%)$ spent $>60$ min during a typical physical activity session.

\section{Sauna and changes in cardiovascular biomarkers}

Table 2 and Fig. 1 show levels of evaluated cardiovascular biomarkers at pre-sauna, immediately after sauna, and $30 \mathrm{~min}$ after sauna. Overall NT-proBNP levels were $46.0 \mathrm{ng} / \mathrm{L}$ before sauna exposure, which increased to $50.5 \mathrm{ng} / \mathrm{L}$ immediately after sauna (median percentage change, $12.00 \% ; p<0.001)$. Increased levels of NT-proBNP remained persistent at 30-min post-sauna, $51.5 \mathrm{ng} / \mathrm{L}$ (median percentage change from pre-sauna to post-30-min sauna, $13.93 \% ; p<0.001$ ) (Table 3). These changes were more evident in males compared with females. Overall, there were no statistically significant changes in levels of hsCRP, creatine kinase, hs-troponin $\mathrm{I}$, and creatine kinase-MBm immediately after sauna and 30 min after sauna. However, levels of creatine kinase increased immediately after sauna in males; from 132.5 to $149.5 \mathrm{U} / \mathrm{L}$ (median relative change, $2.99 \% ; p=0.024$ ). Levels of hs-troponin I seemed to increase immediately after sauna in males, but this change was very small and marginally significant $(0.002-0.005 \mathrm{ng} / \mathrm{mL} ; p=0.058)$ (Table 3).

\section{Discussion}

In this first experimental study to assess the acute effects of Finnish sauna exposure on specific blood-based cardiovascular biomarkers, we have shown that levels of cardiac markers such as NT-proBNP and creatine kinase increase immediately after $30 \mathrm{~min}$ of exposure to sauna. The increase in levels was more pronounced for NT-proBNP and these elevated levels seem to be sustained $30 \mathrm{~min}$ after the sauna exposure. The changes in biomarkers such as creatine kinase were generally more evident in males. There were no statistically significant changes in levels of hsCRP and creatine kinase-MBm both immediately after sauna and post-30-min sauna; though there was a suggestion of an increase in levels of hs-troponin I immediately after sauna in males, but this change was very negligible and marginally significant.

Emerging data suggest that long term or repeated exposure to sauna bathing is associated with reduced risk of cardiovascular outcomes such as hypertension [14, 32], stroke, cardiovascular, and overall mortality [9]. Studies of both Finnish sauna bathing and other passive heat therapies suggest that the protective effects of thermal therapy on these outcomes might be mediated via their beneficial effects on blood pressure, endothelial function, microvascular function, arterial stiffness, vascular resistance, and carotid intima media thickness [1-5, 8, 17-19]. Since levels of blood-based cardiovascular markers such as CRP, creatine kinase, troponin, NT-proBNP, markers of inflammation and oxidative stress, and lipids have been linked to cardiovascular outcomes such as CHD, stroke, and heart failure [33-36], it is biologically plausible that the effects of sauna bathing on cardiovascular function might be mediated through beneficial changes in these cardiac-related biomarkers. Indeed, in two studies that evaluated the effect of Finnish sauna bathing on lipid profile, there were significant decreases in total cholesterol and LDL cholesterol after 2-3 weeks of sauna exposure $[37,38]$. One study suggested that the lipid changes as a result of sauna exposure were similar to that produced by moderate-intensity physical exercise [37]. We have also previously shown that long-term sauna exposure is associated with reduction in levels of markers of inflammation $[15,16]$. 
Table 2 Levels of cardiovascular biomarkers before and after sauna

\begin{tabular}{|c|c|c|c|c|}
\hline & $N(\mathrm{M} / \mathrm{W})$ & Total & $M$ & $F$ \\
\hline \multicolumn{5}{|c|}{ High sensitivity CRP (mg/L) } \\
\hline Pre & $54 / 46$ & $1.26(0.52-2.79)$ & $1.12(0.59-3.31)$ & $1.39(0.48-2.51)$ \\
\hline Post & $53 / 46$ & $1.22(0.51-3.08)$ & $1.09(0.57-3.21)$ & $1.48(0.45-2.86)$ \\
\hline Post 30 min & $51 / 38$ & $1.17(0.53-2.57)$ & $1.17(0.59-2.94)$ & $1.28(0.40-2.42)$ \\
\hline$p$ value* & & 0.852 & 0.768 & 0.535 \\
\hline \multicolumn{5}{|c|}{ Creatine kinase (U/L) } \\
\hline Pre & $54 / 46$ & $114.5(81.0-160.0)$ & $132.5(100.0-189.0)$ & $99.5(71.0-122.0)$ \\
\hline Post & $54 / 46$ & $121.0(88.0-166.0)$ & $149.5(107.0-193.0)$ & $98.0(69.0-130.0)$ \\
\hline Post $30 \mathrm{~min}$ & $50 / 38$ & $115.5(84.5-165.5)$ & $137.0(104.0-195.0)$ & $101.0(74.0-125.0)$ \\
\hline$p$ value* & & 0.037 & 0.027 & 0.059 \\
\hline \multicolumn{5}{|c|}{ High sensitivity troponin I (ng/mL) } \\
\hline Pre & $54 / 46$ & $0.003(0.001-0.015)$ & $0.002(0.001-0.014)$ & $0.005(0.001-0.015)$ \\
\hline Post & $53 / 46$ & $0.005(0.001-0.016)$ & $0.005(0.001-0.022)$ & $0.003(0.001-0.013)$ \\
\hline Post 30 min & $50 / 38$ & $0.002(0.001-0.018)$ & $0.002(0.001-0.015)$ & $0.001(0.001-0.018)$ \\
\hline$p$ value* & & 0.331 & 0.145 & 0.736 \\
\hline \multicolumn{5}{|c|}{ Creatine kinase-MBm (ng/mL) } \\
\hline Pre & $54 / 46$ & $1.39(0.99-2.14)$ & $1.90(1.34-2.67)$ & $1.18(0.71-1.42)$ \\
\hline Post & $53 / 46$ & $1.45(0.97-2.15)$ & $1.93(1.31-2.38)$ & $1.17(0.64-1.60)$ \\
\hline Post $30 \mathrm{~min}$ & $51 / 38$ & $1.50(1.09-2.10)$ & $1.91(1.36-2.43)$ & $1.17(0.82-1.45)$ \\
\hline$p$ value* & & 0.296 & 0.450 & 0.562 \\
\hline \multicolumn{5}{|c|}{ NT-proBNP (ng/L) } \\
\hline Pre & $8 / 12$ & $46.0(32.5-58.0)$ & $48.0(25.5-53.5)$ & $44.0(34.5-74.5)$ \\
\hline Post & $8 / 12$ & $50.5(37.0-66.5)$ & $56.0(31.0-59.0)$ & $46.5(39.5-86.5)$ \\
\hline Post 30 min & $8 / 12$ & $51.5(37.0-70.0)$ & $55.0(31.5-69.5)$ & $48.5(37.0-78.0)$ \\
\hline$p$ value* & & $<0.0001$ & $<0.0001$ & 0.066 \\
\hline
\end{tabular}

$C R P$ C-reactive protein, NT-proBNP N-terminal pro-B-type natriuretic peptide

${ }^{*} p$ value for anova; all values are reported as median (interquartile range)
hsC-reactive protein, $\mathrm{mg} / \mathrm{l}$

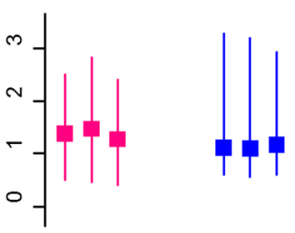

Creatine kinase-MB, ng/ml

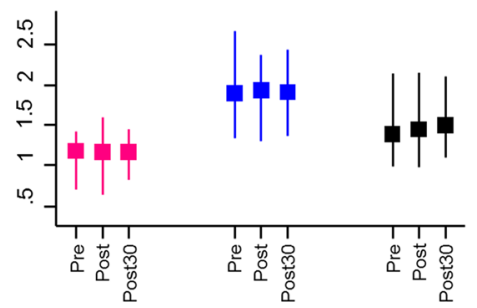

Creatine kinase, U/L

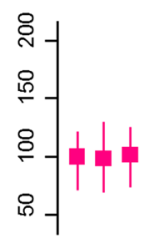

Troponin, $\mathrm{ng} / \mathrm{ml}$

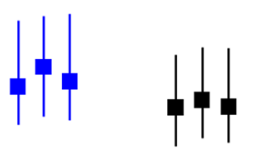

NT-proBNP, ng/ml
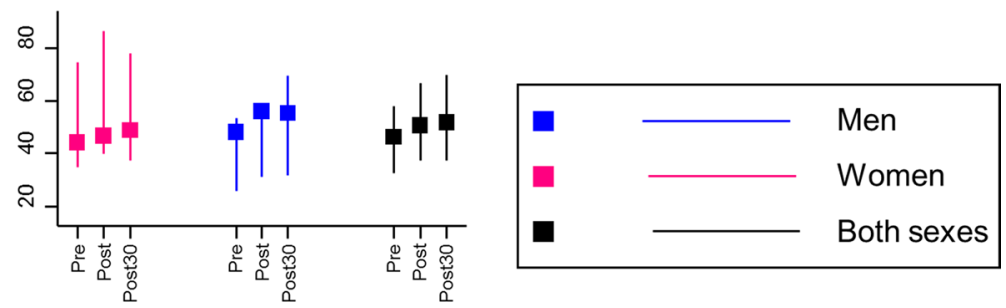

Fig. 1 Levels of cardiovascular biomarkers at pre-sauna, immediately after sauna, and 30 min after sauna. Data are reported as medians (interquartile ranges) 
Table 3 Median percentage changes in cardiovascular biomarkers

\begin{tabular}{|c|c|c|c|}
\hline & Total & $M$ & $F$ \\
\hline \multicolumn{4}{|l|}{ High sensitivity CRP (mg/L) } \\
\hline Post & $1.71(-0.38,5.28)$ & $5.13(1.03,9.49)$ & $-0.80(-3.98,2.79)$ \\
\hline Post $30 \mathrm{~min}$ & $0.62(-1.40,2.58)$ & $3.06(-1.09,5.45)$ & $-0.89(-2.06,1.79)$ \\
\hline$p$ value (post versus pre) & 0.635 & 0.607 & 0.927 \\
\hline$p$ value (post 30 versus pre) & 0.532 & 0.345 & 0.239 \\
\hline \multicolumn{4}{|l|}{ Creatine kinase (U/L) } \\
\hline Post & $1.82(-0.96,3.34)$ & $2.99(1.66,4.76)$ & $-1.61(-3.02,2.78)$ \\
\hline Post $30 \mathrm{~min}$ & $-0.90(-2.70,1.47)$ & $0.00(-1.38,2.40)$ & $-2.70(-5.10,1.68)$ \\
\hline$p$ value (post versus pre) & 0.085 & 0.024 & 0.511 \\
\hline$p$ value (post 30 versus pre) & 0.832 & 0.601 & 0.115 \\
\hline \multicolumn{4}{|c|}{ High sensitivity troponin (ng/mL) } \\
\hline Post & $0.00(0.00,0.00)$ & $0.00(0.00,1.18)$ & $0.00(0.00,5.26)$ \\
\hline Post $30 \mathrm{~min}$ & $0.00(0.00,0.00)$ & $0.00(0.00,0.00)$ & $0.00(-18.61,0.00)$ \\
\hline$p$ value (post versus pre) & 0.269 & 0.058 & 0.788 \\
\hline$p$ value (post 30 versus pre) & 0.576 & 0.779 & 0.296 \\
\hline \multicolumn{4}{|l|}{ Creatine kinase-MBm (ng/mL) } \\
\hline Post & $1.68(-4.77,8.70)$ & $-0.51(-5.86,8.29)$ & $3.30(-7.18,13.06)$ \\
\hline Post $30 \mathrm{~min}$ & $-0.84(-5.86,8.61)$ & $-2.51(-7.77,7.79)$ & $0.51(-9.54,25.86)$ \\
\hline$p$ value (post versus pre) & 0.453 & 0.632 & 0.526 \\
\hline$p$ value (post 30 versus pre) & 0.128 & 0.351 & 0.236 \\
\hline \multicolumn{4}{|l|}{ NT-proBNP (ng/L) } \\
\hline Post & $12.00(9.44,17.70)$ & $17.57(9.38,28.35)$ & $9.79(0.08,14.14)$ \\
\hline Post $30 \mathrm{~min}$ & $13.93(7.61,29.66)$ & $26.42(11.78,41.90)$ & $8.19(-5.50,18.01)$ \\
\hline$p$ value (post versus pre) & $<0.001$ & $<0.001$ & 0.077 \\
\hline$p$ value (post 30 versus pre) & $<0.001$ & $<0.001$ & 0.073 \\
\hline
\end{tabular}

Values are reported as median (95\% confidence intervals); $p$ values are from paired $T$ tests based on the $\log$ transformed variables

$C R P$ C-reactive protein, NT-proBNP N-terminal pro-B-type natriuretic peptide
However, some of the mechanistic pathways implicated for the cardioprotective effects of sauna bathing did not appear to be consistent with our current findings, as we observed only minor changes due to a single sauna session. It is difficult to compare our results in the context of the previous studies, as this is the first study to evaluate the acute effects of a traditional Finnish sauna exposure on circulating levels of these particular cardiovascular risk markers. However, a previously published study demonstrated a delayed increase in plasma levels of atrial natriuretic peptide (ANP) after 20 min of exposure in a Finnish sauna [39].

A number of studies evaluating the effects of other passive heat therapies such as Waon therapy, infrared saunas, intermittent warm water immersion, and whole-body hyperthermia have demonstrated beneficial modulation in levels of blood-based circulating markers of cardiovascular function. While studies on the acute effects of these therapies are sparse, there are a number of studies on the repeated or long-term effects of these thermal therapies. In individuals exposed to about $56 \mathrm{~min}$ of passive heat stress, circulating concentrations of arterial endothelial- and platelet-derived microparticles (which may play a pathogenic role in vascular disease [40-42]) were found to be markedly reduced [21]. Repeated passive heat therapy has also been shown to reduce levels of circulating markers of inflammation and oxidative stress [3, 22-25]. Ohori et al. demonstrated that 3 weeks of repeated thermal treatment (Waon therapy) in patients with chronic heart failure was associated with improvement in levels of BNPs and plasma norepinephrine [43]. In several other studies in which patients with heart failure were treated with infrared-ray sauna therapy for several weeks, decreases in concentrations of BNPs were demonstrated [44, 45]. An essential finding in our study was the elevation in NTproBNP levels after sauna bathing, which may be an indicator of increased workload of the cardiovascular system and heart muscle due to a single 30-min sauna exposure. There is no active function of skeletal muscles during the sauna bathing, which is in contrast to the training response experienced during physical activity. However, increased heart rate increases myocardial workload and oxygen demand similar to physical exercise. Supporting our preliminary findings, in a previous exercise-exposure study, a significant increase 
in NT-proBNP was observed after 10-km recreational running exercise session [46]. N-terminal pro-B-type natriuretic peptides, which are the more stable by-products of circulating B-type natriuretic peptides, are known to play a role in the regulation of blood pressure and sodium balance [47]. Above the reference range, increased concentrations of NT-proBNP have been recommended for the diagnosis and treatment guidance of heart failure [48, 49]. Recent evidence suggests that information on NT-proBNP is predictive of first-onset heart failure, CHD, and stroke [33]. Another finding in our study was a slight increase in levels of hstroponin I in males immediately after sauna, but the difference was marginally significant. Troponin is released from the cytosolic pool of the myocytes and it may be released during prolonged ischemia with degradation of actin and myosin filaments and it has been even used as a marker of minor cardiac muscle injury [50]. Compared with the older troponin assays, hs-troponin I assays improve the speed of diagnosis and are well-suited for detecting sub-clinical cardiac structural abnormalities [50, 51]. High-sensitivity cardiac troponins have also been suggested to be prognostic biomarkers for cardiovascular events in normal- and highrisk general populations [52]. The minor changes in levels of these markers could be due to the short-term nature of the sauna exposure (only $30 \mathrm{~min}$ ). Previous studies of other passive heat therapies with longer exposure time have demonstrated marked changes in levels of some of these circulating biomarkers [43, 44]. Long-term intervention studies are indeed warranted to study the effects of sauna bathing on these cardiac-specific biomarkers.

To our knowledge, we have conducted the first study to evaluate the acute effects of 30-min sauna exposure on emerging biomarkers for cardiovascular function, based on traditional hot and dry Finnish sauna bathing which is a different exposure compared to other passive heat therapies such as warm water immersion, Waon therapy, and infrared heat, which are characterized by lower temperatures. Given the experimental setting of the current study, the number of study subjects recruited was adequate to assess any meaningful clinical changes in indices evaluated. The intervention simulated a typical dry and hot Finnish sauna session which lasted for $30 \mathrm{~min}$ and no adverse events occurred duration the entire duration of the study. These observations suggest that $30 \mathrm{~min}$ of sauna bathing can be considered a safe activity for the cardiovascular system, findings which are consistent with reports that regular sauna bathing can be safely recommended for majority of healthy people and patients with stable heart disease [32]. A number of limitations deserve consideration. A major limitation was that study participants were not sauna-naive users or did not include non-sauna users, which could have caused biases as the intervention is not novel to study participants. This situation could not be avoided, because the majority of the Finnish population are sauna users, given that sauna bathing is embedded in the tradition. The intervention was short-term and we employed a before- and after-design without the use of a control; however, this study was designed to be a pilot study and was exploratory in nature given the novel nature of the topic. We had measurements of NT-proBNP in only a small number of participants, which was due to the costs associated with such measurements. Follow-up period of recovery was limited to a 30-min period. Due to the novel study protocol which focused on acute changes in inflammatory, muscle and cardiac biomarkers, we did not assess prolonged or long-lasting changes hours or days after sauna exposure.

\section{Conclusions}

Our experimental study suggests that levels of NT-proBNP and creatine kinase increase after short-term sauna exposure. These changes are more evident in males. Long-term interventional studies are warranted to evaluate if these biomarkers are involved in pathways underlying the protective associations of sauna bathing with adverse cardiovascular outcomes.

Acknowledgements This study was supported by the Tekes, the Finnish Funding Agency for Technology and Innovation, Helsinki, Finland.

\section{Compliance with ethical standards}

Conflict of interest The authors have no conflict of interest to disclose.

Open Access This article is distributed under the terms of the Creative Commons Attribution 4.0 International License (http://creativeco mmons.org/licenses/by/4.0/), which permits unrestricted use, distribution, and reproduction in any medium, provided you give appropriate credit to the original author(s) and the source, provide a link to the Creative Commons license, and indicate if changes were made.

\section{References}

1. Brunt VE, Howard MJ, Francisco MA, Ely BR, Minson CT (2016) Passive heat therapy improves endothelial function, arterial stiffness and blood pressure in sedentary humans. J Physiol 594(18):5329-5342

2. Brunt VE, Eymann TM, Francisco MA, Howard MJ, Minson CT (2016) Passive heat therapy improves cutaneous microvascular function in sedentary humans via improved nitric oxide-dependent dilation. J Appl Physiol (1985) 121(3):716-723

3. Fujita S, Ikeda Y, Miyata M, Shinsato T, Kubozono T, Kuwahata S, Hamada N, Miyauchi T, Yamaguchi T, Torii H, Hamasaki S, Tei C (2011) Effect of Waon therapy on oxidative stress in chronic heart failure. Circ J 75(2):348-356

4. Kuwahata S, Miyata M, Fujita S, Kubozono T, Shinsato T, Ikeda Y, Hamasaki S, Kuwaki T, Tei C (2011) Improvement of autonomic nervous activity by Waon therapy in patients with chronic heart failure. J Cardiol 57(1):100-106 
5. Imamura M, Biro S, Kihara T, Yoshifuku S, Takasaki K, Otsuji Y, Minagoe S, Toyama Y, Tei C (2001) Repeated thermal therapy improves impaired vascular endothelial function in patients with coronary risk factors. J Am Coll Cardiol 38(4):1083-1088

6. Perasalo J (1988) Traditional use of the sauna for hygiene and health in Finland. Ann Clin Res 20(4):220-223

7. Valtakari P (1988) The sauna and bathing in different countries. Ann Clin Res 20(4):230-235

8. Laukkanen T, Kunutsor SK, Zaccardi F, Lee E, Willeit P, Khan H, Laukkanen JA (2018) Acute effects of sauna bathing on cardiovascular function. J Hum Hypertens 32(2):129-138

9. Laukkanen T, Khan H, Zaccardi F, Laukkanen JA (2015) Association between sauna bathing and fatal cardiovascular and allcause mortality events. JAMA Intern Med 175(4):542-548

10. Kunutsor SK, Khan H, Zaccardi F, Laukkanen T, Willeit P, Laukkanen JA (2018) Sauna bathing reduces the risk of stroke in Finnish men and women: a prospective cohort study. Neurology 90(22):e1937-e1944

11. Laukkanen T, Kunutsor S, Kauhanen J, Laukkanen JA (2017) Sauna bathing is inversely associated with dementia and Alzheimer's disease in middle-aged Finnish men. Age Age 46(2):245-249

12. Kunutsor SK, Laukkanen T, Laukkanen JA (2017) Sauna bathing reduces the risk of respiratory diseases: a long-term prospective cohort study. Eur J Epidemiol 32(12):1107-1111

13. Kunutsor SK, Laukkanen T, Laukkanen JA (2017) Frequent sauna bathing may reduce the risk of pneumonia in middle-aged Caucasian men: the KIHD prospective cohort study. Respir Med 132:161-163

14. Zaccardi F, Laukkanen T, Willeit P, Kunutsor SK, Kauhanen J, Laukkanen JA (2017) Sauna bathing and incident hypertension: a prospective cohort study. Am J Hypertens 30(11):1120-1125

15. Laukkanen JA, Laukkanen $T$ (2018) Sauna bathing and systemic inflammation. Eur J Epidemiol 33(3):351-353

16. Kunutsor SK, Laukkanen T, Laukkanen J (2018) Longitudinal associations of sauna bathing with inflammation and oxidative stress: the KIHD prospective cohort study. Ann Med. https:// doi.org/10.1080/07853890.2018.1489143

17. Gayda M, Paillard F, Sosner P, Juneau M, Garzon M, Gonzalez M, Belanger M, Nigam A (2012) Effects of sauna alone and postexercise sauna baths on blood pressure and hemodynamic variables in patients with untreated hypertension. J Clin Hypertens (Greenwich) 14(8):553-560

18. Radtke T, Poerschke D, Wilhelm M, Trachsel LD, Tschanz H, Matter F, Jauslin D, Saner H, Schmid JP (2016) Acute effects of Finnish sauna and cold-water immersion on haemodynamic variables and autonomic nervous system activity in patients with heart failure. Eur J Prev Cardiol 23(6):593-601

19. Lee E, Laukkanen T, Kunutsor SK, Khan H, Willeit P, Zaccardi F, Laukkanen JA (2018) Sauna exposure leads to improved arterial compliance: findings from a non-randomised experimental study. Eur J Prev Cardiol 25(2):130-138

20. Kukkonen-Harjula K, Kauppinen K (1988) How the sauna affects the endocrine system. Ann Clin Res 20(4):262-266

21. Bain AR, Ainslie PN, Bammert TD, Hijmans JG, Sekhon M, Hoiland RL, Fluck D, Donnelly J, DeSouza CA (2017) Passive heat stress reduces circulating endothelial and platelet microparticles. Exp Physiol 102(6):663-669

22. Eymann TM, Brunt VE, Wiedenfield-Needham KM, Minson FCT (2016) Passive heat therapy improves nitric oxide signaling and oxidative stress. Int J Exerc Sci Conf Proc 8(4):48

23. Faulkner SH, Jackson S, Fatania G, Leicht CA (2017) The effect of passive heating on heat shock protein 70 and interleukin-6: a possible treatment tool for metabolic diseases? Temperature (Austin) 4(3):292-304
24. Lee EC, Watson G, Casa D, Armstrong LE, Kraemer W, Vingren JL, Spiering BA, Maresh CM (2012) Interleukin-6 responses to water immersion therapy after acute exercise heat stress: a pilot investigation. J Athl Train 47(6):655-663

25. Masuda A, Miyata M, Kihara T, Minagoe S, Tei C (2004) Repeated sauna therapy reduces urinary 8-epi-prostaglandin F(2alpha). Jpn Heart J 45(2):297-303

26. Brunt VE, Jeckell AT, Ely BR, Howard MJ, Thijssen DH, Minson CT (2016) Acute hot water immersion is protective against impaired vascular function following forearm ischemia-reperfusion in young healthy humans. Am J Physiol Regul Integr Comp Physiol 311(6):R1060-R1067

27. Thomas KN, van Rij AM, Lucas SJ, Cotter JD (2017) Lower-limb hot-water immersion acutely induces beneficial hemodynamic and cardiovascular responses in peripheral arterial disease and healthy, elderly controls. Am J Physiol Regul Integr Comp Physiol 312(3):R281-R291

28. Tei C, Horikiri Y, Park JC, Jeong JW, Chang KS, Toyama Y, Tanaka N (1995) Acute hemodynamic improvement by thermal vasodilation in congestive heart failure. Circulation 91(10):2582-2590

29. Romero SA, Gagnon D, Adams AN, Cramer MN, Kouda K, Crandall CG (2017) Acute limb heating improves macro- and microvascular dilator function in the leg of aged humans. Am J Physiol Heart Circ Physiol 312(1):H89-H97

30. Kaldur T, Unt E, Oopik V, Zilmer M, Eha J, Paapstel K, Kals J (2016) The acute effects of passive heat exposure on arterial stiffness, oxidative stress, and inflammation. Medicina (Kaunas) 52(4):211-216

31. Geraci M, Alston RD, Birch JM (2013) Median percent change: a robust alternative for assessing temporal trends. Cancer Epidemiol 37(6):843-849

32. Hannuksela ML, Ellahham S (2001) Benefits and risks of sauna bathing. Am J Med 110(2):118-126

33. Natriuretic Peptides Studies Collaboration, Willeit P, Kaptoge S, Welsh P, Butterworth AS, Chowdhury R, Spackman SA, Pennells L, Gao P, Burgess S, Freitag DF, Sweeting M, Wood AM, Cook NR, Judd S, Trompet S, Nambi V, Olsen MH, Everett BM, Kee F, Arnlov J, Salomaa V, Levy D, Kauhanen J, Laukkanen JA, Kavousi M, Ninomiya T, Casas JP, Daniels LB, Lind L, Kistorp CN, Rosenberg J, Mueller T, Rubattu S, Panagiotakos DB, Franco OH, de Lemos JA, Luchner A, Kizer JR, Kiechl S, Salonen JT, Goya Wannamethee S, de Boer RA, Nordestgaard BG, Andersson J, Jorgensen T, Melander O, Ballantyne ChM, DeFilippi C, Ridker PM, Cushman M, Rosamond WD, Thompson SG, Gudnason V, Sattar N, Danesh J, Di Angelantonio E (2016) Natriuretic peptides and integrated risk assessment for cardiovascular disease: an individual-participant-data meta-analysis. Lancet Diabetes Endocrinol 4(10):840-849

34. Emerging Risk Factors Collaboration, Kaptoge S, Di Angelantonio E, Pennells L, Wood AM, White IR, Gao P, Walker M, Thompson A, Sarwar N, Caslake M, Butterworth AS, Amouyel P, Assmann G, Bakker SJ, Barr EL, Barrett-Connor E, Benjamin EJ, Bjorkelund C, Brenner H, Brunner E, Clarke R, Cooper JA, Cremer P, Cushman M, Dagenais GR, D'Agostino RB Sr, Dankner R, Davey-Smith G, Deeg D, Dekker JM, Engstrom G, Folsom AR, Fowkes FG, Gallacher J, Gaziano JM, Giampaoli S, Gillum RF, Hofman A, Howard BV, Ingelsson E, Iso H, Jorgensen T, Kiechl S, Kitamura A, Kiyohara Y, Koenig W, Kromhout D, Kuller LH, Lawlor DA, Meade TW, Nissinen A, Nordestgaard BG, Onat A, Panagiotakos DB, Psaty BM, Rodriguez B, Rosengren A, Salomaa V, Kauhanen J, Salonen JT, Shaffer JA, Shea S, Ford I, Stehouwer CD, Strandberg TE, Tipping RW, Tosetto A, Wassertheil-Smoller S, Wennberg P, Westendorp RG, Whincup PH, Wilhelmsen L, Woodward M, Lowe GD, Wareham NJ, Khaw KT, Sattar N, Packard CJ, Gudnason V, Ridker PM, Pepys MB, Thompson SG, 
Danesh J (2012) C-reactive protein, fibrinogen, and cardiovascular disease prediction. N Engl J Med 367(14):1310-1320

35. Emerging Risk Factors Collaboration, Di Angelantonio E, Gao P, Pennells L, Kaptoge S, Caslake M, Thompson A, Butterworth AS, Sarwar N, Wormser D, Saleheen D, Ballantyne CM, Psaty BM, Sundstrom J, Ridker PM, Nagel D, Gillum RF, Ford I, Ducimetiere P, Kiechl S, Koenig W, Dullaart RP, Assmann G, D'Agostino RB Sr, Dagenais GR, Cooper JA, Kromhout D, Onat A, Tipping RW, Gomez-de-la-Camara A, Rosengren A, Sutherland SE, Gallacher J, Fowkes FG, Casiglia E, Hofman A, Salomaa V, BarrettConnor E, Clarke R, Brunner E, Jukema JW, Simons LA, Sandhu M, Wareham NJ, Khaw KT, Kauhanen J, Salonen JT, Howard WJ, Nordestgaard BG, Wood AM, Thompson SG, Boekholdt SM, Sattar N, Packard C, Gudnason V, Danesh J (2012) Lipidrelated markers and cardiovascular disease prediction. JAMA 307(23):2499-2506

36. Di Angelantonio E, Chowdhury R, Sarwar N, Ray KK, Gobin R, Saleheen D, Thompson A, Gudnason V, Sattar N, Danesh J (2009) B-type natriuretic peptides and cardiovascular risk: systematic review and meta-analysis of 40 prospective studies. Circulation 120(22):2177-2187

37. Gryka D, Pilch W, Szarek M, Szygula Z, Tota L (2014) The effect of sauna bathing on lipid profile in young, physically active, male subjects. Int J Occup Med Environ Health 27(4):608-618

38. Pilch W, Szygula Z, Klimek AT, Palka T, Cison T, Pilch P, Torii $M$ (2010) Changes in the lipid profile of blood serum in women taking sauna baths of various duration. Int J Occup Med Environ Health 23(2):167-174

39. Leppaluoto J, Arjamaa O, Vuolteenaho O, Ruskoaho H (1991) Passive heat exposure leads to delayed increase in plasma levels of atrial natriuretic peptide in humans. J Appl Physiol (1985) 71(2):716-720

40. Stepien E, Stankiewicz E, Zalewski J, Godlewski J, Zmudka K, Wybranska I (2012) Number of microparticles generated during acute myocardial infarction and stable angina correlates with platelet activation. Arch Med Res 43(1):31-35

41. Horstman LL, Jy W, Jimenez JJ, Ahn YS (2004) Endothelial microparticles as markers of endothelial dysfunction. Front Biosci 9:1118-1135

42. Martinez MC, Tesse A, Zobairi F, Andriantsitohaina R (2005) Shed membrane microparticles from circulating and vascular cells in regulating vascular function. Am J Physiol Heart Circ Physiol 288(3):H1004-H1009

43. Ohori T, Nozawa T, Ihori H, Shida T, Sobajima M, Matsuki A, Yasumura S, Inoue H (2012) Effect of repeated sauna treatment on exercise tolerance and endothelial function in patients with chronic heart failure. Am J Cardiol 109(1):100-104

44. Kihara T, Biro S, Imamura M, Yoshifuku S, Takasaki K, Ikeda Y, Otuji Y, Minagoe S, Toyama Y, Tei C (2002) Repeated sauna treatment improves vascular endothelial and cardiac function in patients with chronic heart failure. J Am Coll Cardiol 39(5):754-759

45. Miyamoto H, Kai H, Nakaura H, Osada K, Mizuta Y, Matsumoto A, Imaizumi T (2005) Safety and efficacy of repeated sauna bathing in patients with chronic systolic heart failure: a preliminary report. J Card Fail 11(6):432-436

46. Kim JH, Ko YA, Hedley J, MacNamara J, Awad M, Taylor W, Healy S, Aida H, Le NA, Wilson PW, White M, Sperling LS, Wilson JS Jr, Baggish AL (2017) The impact of moderate distance recreational running and ageing on cardiac physiology. Heart 103(3):219-226

47. Levin ER, Gardner DG, Samson WK (1998) Natriuretic peptides. N Engl J Med 339(5):321-328

48. Yancy CW, Jessup M, Bozkurt B, Butler J, Casey DE Jr, Drazner MH, Fonarow GC, Geraci SA, Horwich T, Januzzi JL, Johnson MR, Kasper EK, Levy WC, Masoudi FA, McBride PE, McMurray JJ, Mitchell JE, Peterson PN, Riegel B, Sam F, Stevenson LW, Tang WH, Tsai EJ, Wilkoff BL, American College of Cardiology F, American Heart Association Task Force on Practice G (2013) 2013 ACCF/AHA guideline for the management of heart failure: a report of the American College of Cardiology Foundation/American Heart Association Task Force on Practice Guidelines. J Am Coll Cardiol 62(16):e147-e239

49. McMurray JJ, Adamopoulos S, Anker SD, Auricchio A, Bohm M, Dickstein K, Falk V, Filippatos G, Fonseca C, Gomez-Sanchez MA, Jaarsma T, Kober L, Lip GY, Maggioni AP, Parkhomenko A, Pieske BM, Popescu BA, Ronnevik PK, Rutten FH, Schwitter J, Seferovic P, Stepinska J, Trindade PT, Voors AA, Zannad F, Zeiher A (2012) ESC Guidelines for the diagnosis and treatment of acute and chronic heart failure 2012: the Task Force for the Diagnosis and Treatment of Acute and Chronic Heart Failure 2012 of the European Society of Cardiology. Developed in collaboration with the Heart Failure Association (HFA) of the ESC. Eur Heart J 33(14): 1787-1847

50. Keller T, Zeller T, Ojeda F, Tzikas S, Lillpopp L, Sinning C, Wild P, Genth-Zotz S, Warnholtz A, Giannitsis E, Mockel M, Bickel C, Peetz D, Lackner K, Baldus S, Munzel T, Blankenberg S (2011) Serial changes in highly sensitive troponin I assay and early diagnosis of myocardial infarction. JAMA 306(24):2684-2693

51. Keller T, Zeller T, Peetz D, Tzikas S, Roth A, Czyz E, Bickel C, Baldus S, Warnholtz A, Frohlich M, Sinning CR, Eleftheriadis MS, Wild PS, Schnabel RB, Lubos E, Jachmann N, Genth-Zotz S, Post F, Nicaud V, Tiret L, Lackner KJ, Munzel TF, Blankenberg S (2009) Sensitive troponin I assay in early diagnosis of acute myocardial infarction. N Engl J Med 361(9):868-877

52. McCarthy CP, Yousuf O, Alonso A, Selvin E, Calkins H, McEvoy JW (2017) High-sensitivity troponin as a biomarker in heart rhythm disease. Am J Cardiol 119(9):1407-1413 